\title{
THE COMPARISON OF GENERAL AND REGIONAL ANAESTHESIA REGARDING 1-YEAR MORTALITY IN DIABETIC PATIENTS UNDERGOING BELOW THE KNEE AMPUTATION Oya Yalcin Cok', Salih Beyaz², Cagla Bali'
}

Department of Anesthesiology ${ }^{1} \&$ Department of Orthopedics and Traumatology ${ }^{2}$, Baskent University, Adana Dr Turgut Noyan Education and Research Center, Adana, Turkey

\section{Background and aims}

Diabetic patients undergoing below the knee amputation often represent with severe concomitant conditions. Intraoperative anaesthetic management may also have an impact on overall morbidity and morbidity. However, there still exists controversial information on the superiority of any anaesthetic technique over the other. The aim of this study was to compare the general and regional anaesthesia regarding 1-year mortality and related causative factors in diabetic patients undergoing below-the knee amputation (BKA).

\section{Methods}

- Diabetic patients undergoing below the knee amputation between 2006 and 2018

- Recorded data

- Demographic data

- Anaesthesia type; general (Group GA), regional (Group RA)

- type of RA ; neuraxial, peripheral nerve

- Haemodialysis requirement

- Duration until mortality

\section{Results}

- 418 patients in 583 files were included to the study

- Demographic data was displayed in Table 1.

- Patients in Group GA had significantly short survival duration in comparison to Group RA (55.4 \pm 8.7 vs $91.2 \pm 10.5$, days, $p=0.010)$.

- Number of patients in Group Ga and RA who died following BKA during the first year was as Fig1.
Table 1. Age, gender and survival duration of the patients

\begin{tabular}{|c|c|c|c|c|}
\hline & $\begin{array}{c}\text { General } \\
\text { anesthesia } \\
(n=244)\end{array}$ & \multicolumn{2}{|c|}{ Regional anesthesia } & \\
& $\begin{array}{c}\text { Neuraxial } \\
(n=121)\end{array}$ & $\begin{array}{c}\text { Peripheral } \\
\text { nerve } \\
(n=53)\end{array}$ & $p$ \\
\hline Age (years) & $64.6 \pm 0.7$ & $65.3 \pm 1.09$ & $65.2 \pm 1.9$ & $>0.05$ \\
\hline $\begin{array}{c}\text { Gender (M/F) } \\
\text { Total } \\
\text { Exitus }\end{array}$ & $158 / 86$ & $77 / 44$ & $23 / 30$ & 0.013 \\
\hline $\begin{array}{c}\text { Survival } \\
\text { (days) }\end{array}$ & $53 / 48$ & $41 / 32$ & $16 / 20$ & $>0.05$ \\
\hline
\end{tabular}

Age and survival duration were stated as mean \pm SE whereas gender was stated in numbers

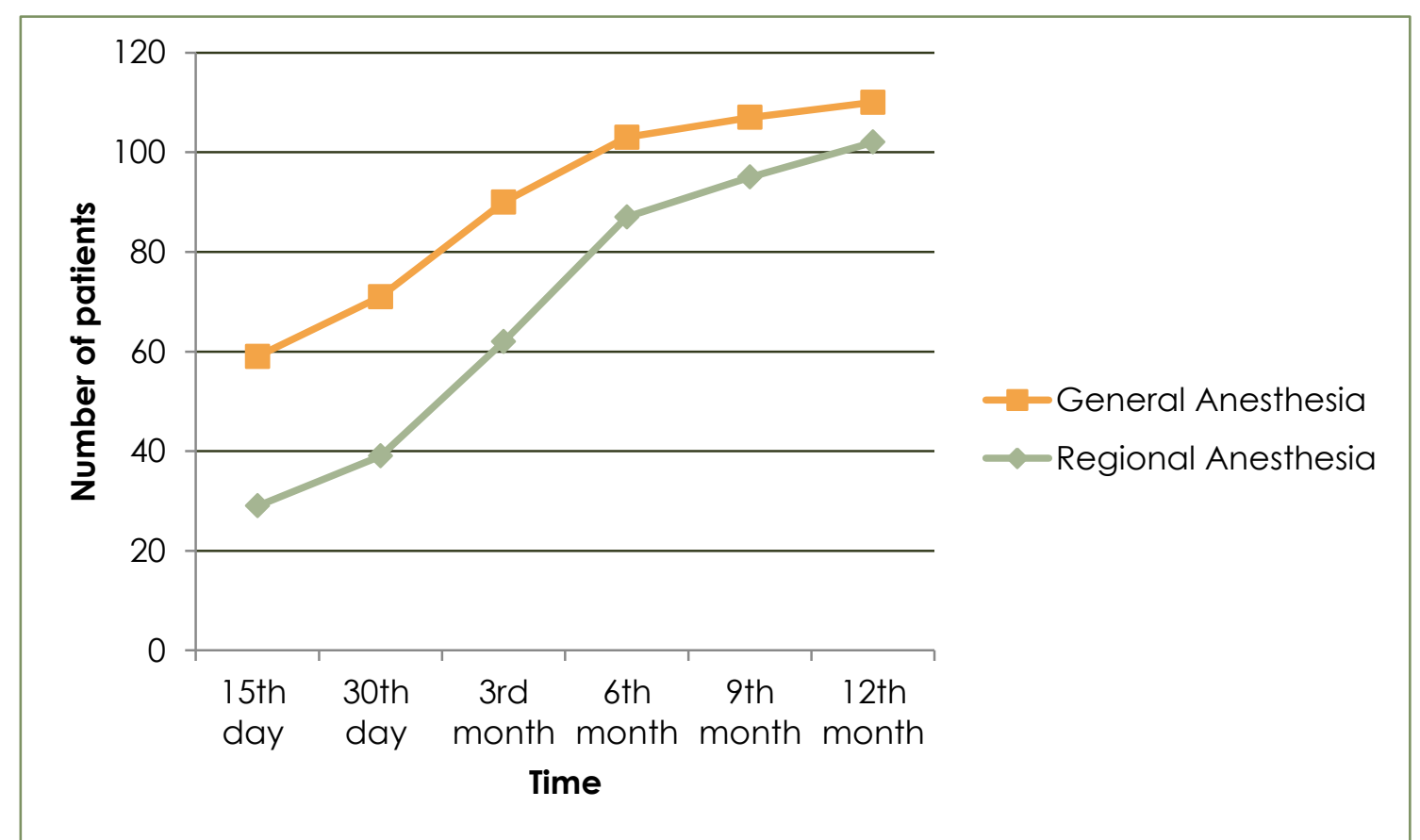

Fig1. Number of patients who died following BKA during the first year

\section{Conclusions}

According to the results of this study, neuraxial techniques provide longer survival duration in the first postoperative year in diabetic patients with severe comorbidities undergoing below the knee amputation in comparison to general anaesthesia and peripheral nerve blocks. However such results should still be interpreted cautiously, since there may exist disguised reasons simultaneously affecting the selection of the anaesthetic technique and expected mortality rates.

1. Survival evaluation of the patients with diabetic major lower-extremity amputations. Musculoskelet Surg. 2016;100(2):145-8

2. Mortality After Nontraumatic Major Amputation Among Patients With Diabetes and Peripheral Vascular Disease: A Systematic Review. J Foot Ankle Surg. 2016:55(3):591-9

3. The effect of anesthesia type on major lower extremity amputation in functionally impaired elderly patients. J Vasc Surg. 2016;63(3):696-701 